\title{
Wideband Planar Array Antenna Based on SCRLH- TL for Airborne Synthetic Aperture Radar Application
}

\author{
Mohammad Alibakhshikenari ${ }^{1 *}$, Bal Singh Virdee ${ }^{2}$, and Ernesto Limiti ${ }^{1}$ \\ ${ }^{1}$ Electronics Engineering Department, University of Rome "Tor Vergata", Via del politecnico 1, 00133 Rome, Italy \\ ${ }^{2}$ London Metropolitan University, Center for Communications Technology \& Mathematics, School of Computing \& Digital \\ Media, London N7 8DB, UK \\ *alibakhshikenari@ing.uniroma2.it
}

\begin{abstract}
This paper presents empirical results of a novel planar microstrip array antenna based on a simplified composite right/left-handed transmission-line (SCRLH-TL) for application in circularly polarized synthetic aperture radar (CP-SAR) systems operated in UHF, $\mathrm{L}, \mathrm{S}$ and C-Bands. The array antenna consists of $6 \times 6$ matrix of spiral shaped radiating elements that are excited through proximity-coupled, single feed-line. Pattern synthesis technique is used to determine the excitation coefficients (amplitude and phase) to apply to the individual array elements to achieve the required pattern shape. The array antenna has dimensions of $111.5 \times 96.06 \mathrm{~mm}^{2}$. The measured impedance bandwidth of the antenna is $3.85 \mathrm{GHz}$ for $\mathrm{S}_{11}<-10 \mathrm{~dB}$ from $300 \mathrm{MHz}$ to $4.15 \mathrm{GHz}$, corresponding to a fractional bandwidth of $173 \%$. Maximum gain and radiation efficiency measured are $4.8 \mathrm{dBi}$ and $79.5 \%$, respectively, at $2.40 \mathrm{GHz}$. The antenna has a 3-dB axial-ratio bandwidth of 3.94 GHz from $144 \mathrm{MHz}$ to 4.66 GHz. The antenna's beamwidth in azimuth and elevation planes vary between $60^{\circ}$ and $120^{\circ}$ across its operational frequency range from $300 \mathrm{MHz}$ to $4.15 \mathrm{GHz}$. The antenna design fulfills the challenging electrical and physical specifications required for CP-SAR employed onboard unmanned aerial vehicle (UAV).
\end{abstract}

Key Terms - Planar array antenna, synthetic aperture radar, simplified composite right/left-handed transmission-line, metamaterials.

\section{INTRODUCTION}

Nowadays, radars are used extensively for numerous civilian and military applications including automotive, aircraft control and navigation, imaging, safety systems, and guidance [1][2]. Phased array imaging radars employ long antennas to generate a fan beam that illuminates the ground below. Track resolution of these radars is determined by the beamwidth while the across resolution is determined by the pulse length. Antenna dimensions and mass of such radars need to be confined especially in airborne and space-borne systems. This can severely limit the antenna aperture of the radar and hence degrade its resolution. This limitation is nowadays circumvented by using signal processing techniques in synthetic aperture radars (SAR) [3]. The advantage of SAR is that it permits the use of lower frequencies without significantly compromising the radar's resolution. In SAR the Doppler-shifted sequence of echoes is matchedfiltered with an azimuth shift to realize a high resolution image.

Linearly polarized (LP) antennas were first used in SAR systems [4]. However, as the RF signal propagation in the troposphere is different from that in free-space as the refractive index varies with altitude, this phenomenon causes atmospheric refraction effects. This can generate phase errors in the signal that affects the imaging performance of SAR typically spatially variant defocus blur. Hence, for space application circular polarization synthetic aperture radar (CP-SAR) needs to be used to avoid Faraday rotation effect in order to void image degradation [5]-[7].

Antennas for synthetic aperture radar systems in addition to meeting demanding characteristics of wide bandwidth, circular polarization with high purity, reduced side-lobe level and back radiation, must also need to have a low profile and light weight. Although microstrip based antennas are able to meet the latter requirements however they have undesirable properties of narrowband and mediocre radiation efficiencies. These disadvantages make microstrip antennas unsuitable for SAR systems. Hence, several bandwidth enhancement techniques have been reported in literature including utilization of: (1) parasitic patches [8]; (2) near resonant aperture with thick antenna substrate [9]; stacked patches where a parasitic element is placed above a lower patch [10]; and composite right/lefthanded transmission-lines (CRLH-TLs) [11]-[15]. Bandwidth and radiation efficiency enhancement in the case of using CRLH-TL structures can be achieved by simply using a thicker substrate with lower dielectric constant [9]. Further improvement can be achieved by optimizing the series left-handed (LH) capacitance $\left(C_{L}\right)$ and shunt LH inductance $\left(L_{L}\right)$ constituting the CRLH-TL structure [12]. However, when the substrate thickness exceeds about $0.005 \lambda_{0}$, the increased inductance of the feed-line can deteriorate the impedance matching to the 
antenna. This problem can be resolved by modifying the feed-line to a strip-line feed, in which the increased inductive reactance of the probe can be compensated by the capacitance of the feed-line [16].

In [17] multiband metamaterial based microstrip antenna design is described for WLAN and WiMAX applications. The antenna is composed of a rectangle patch with complementary split ring resonator slots over a conventional ground plane. This antenna it exhibits $S_{11}$ $<-10 \mathrm{~dB}$ only over $2.4-2.48 \mathrm{GHz}, 3.3-3.9 \mathrm{GHz}$ and 5.15$5.7 \mathrm{GHz}$, and polarity of the antenna is unspecified. The multiband antenna in [18] employs dual composite right left handed transmission line to provide $\mathrm{S}_{11}<-10 \mathrm{~dB}$ at $2.45,3.60$ and $5.60 \mathrm{GHz}$, and polarization of the antenna is unspecified. In [19] a metal patch radiator in the shape of either square, hexagonal or star is located above a dielectric substrate loaded with an arrangement of complementary strip ring resonators. Only the patch is excited through a feed-line from the bottom. Only simulation results are presented. The square patch antenna is shown to resonant at 2.94, 5, 5.91, 6.5 and $8.23 \mathrm{GHz}$ with a directive gain of $5.29 \mathrm{dBi}$ at $2.94 \mathrm{GHz}$. The hexagonal patch antenna resonates at 4.3, 4.9, 5, 5.7, $8 \mathrm{GHz}$ with directive gain of $5.09 \mathrm{dBi}$ at $4.3 \mathrm{GHz}$. The star patch antenna resonates at 3.29, 5.11, 5.4, 5.9, 6.62, $8.1 \mathrm{GHz}$ with gain of $5.86 \mathrm{dBi}$ at $3.29 \mathrm{GHz}$. No polarization information is presented.

This paper presents a slot spiral which is etched on a microstrip medium that has properties of a SCRLH-TL. The slot spiral is used as a unit-cell radiating element in the design and implementation of an antenna for SAR applications. The single radiating element has a fractional bandwidth of $25 \%$ for VSWR $<2$. However, when integrated in the antenna comprising of an arrangement of $6 \times 6$ radiating elements the antenna is shown to exhibit a fractional bandwidth of $173 \%$. The proposed antenna configuration eases fabrication and is suitable for the mass production.

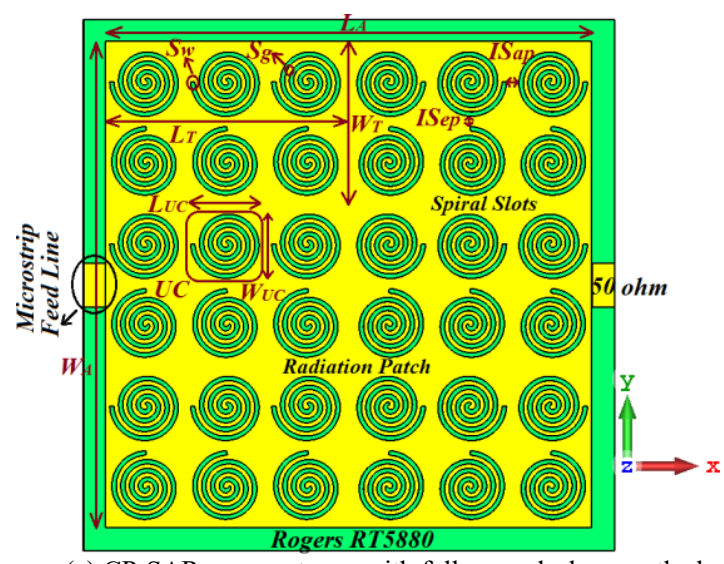

(a) CP-SAR array antenna with full ground-plane on the backside.
The array antenna has a measured operational bandwidth of $173 \%$, which is not possible with a waveguide slotted array. Feeder network of this array antenna has been configured in strip-line to isolate the feed network from the radiating patches in order to shield spurious radiation from the feed-line from affecting the radiation of the array antenna. Furthermore, in the proposed configuration the substrate can be used as a radome for environmental protection. Compared to previous multiband antennas [17]-[19] the proposed antenna exhibits the following unique features: (i) wideband coverage from $300 \mathrm{MHz}$ to $4.15 \mathrm{GHz}$, corresponding to a fractional bandwidth of $173 \%$; (ii) average gain of $2.33 \mathrm{dBi}$ (maximum of $4.8 \mathrm{dBi}$ at 2.40 $\mathrm{GHz}$ ); (iii) average efficiency of $53.7 \%$ (maximum of $79.5 \%$ at $2.40 \mathrm{GHz}$ ); and (iv) $3-\mathrm{dB}$ axial-ratio bandwidth of $3.94 \mathrm{GHz}$ from $144 \mathrm{MHz}$ to $4.66 \mathrm{GHz}$. The antenna design fulfils the challenging specifications for CP-SAR onboard unmanned aerial vehicle (UAV).

\section{Circularly Polarized SAR AntennA}

Specifications for the proposed CP-SAR system are shown in Table I for application in UAV. Operating bands chosen for the CP-SAR are: UHF $(300 \mathrm{MHz}$ and $850 \mathrm{MHz})$, L-band (1.5 GHz), S-band (2.4 GHz, 3.15 $\mathrm{GHz}$ and $3.8 \mathrm{GHz}$ ), and C-band (4.15 GHz). The long wavelengths at UHF should enable the radar to penetrate the foliage and image features on the Earth surface as well as detect underground facilities [11]. To ensure circularly polarized transmit and receive signals the bandwidth of the proposed CP-SAR antenna needs to ensure low axial-ratio (AR). The antenna will need to have a return-loss lower than $10 \mathrm{~dB}$ to ensure the input impedance of the antenna is matched. The proposed CPSAR antenna design is consistent with the physical requirement for deployment in airborne or satellite systems.



(b) The proposed CP-SAR array antenna onboard a UAV. 
Fig. 1. Configuration of the proposed rectangular patch microstrip array antenna consisting of $6 \times 6$ spiral elements with direct feed-line. Each block of $2 \times 3$ and $2 \times 6$ elements were analyzed separately for amplitude and phase performance. The blocks were then combined in a $6 \times 6$ element planar array.

Table I. Specifications of the proposed CP-SAR.

\begin{tabular}{|c|c|}
\hline Parameters & Specifications \\
\hline & $300 \mathrm{MHz}$ and $850 \mathrm{MHz}$ (UHF-band) \\
Frequency & $1.5 \mathrm{GHz}$ (L-band) \\
& $2.4 \mathrm{GHz}, 3.15 \mathrm{GHz}$ and $3.8 \mathrm{GHz}$ (S-band) \\
& $4.15 \mathrm{GHz}$ (C-band) \\
\hline Polarization & Transmitter: RHCP or LHCP \\
& Receiver: RHCP + LHCP \\
\hline Gain & $>4.5 \mathrm{dBi}$ \\
\hline Efficiency & $>79 \%$ \\
\hline Axial-ratio (AR) & $<3 \mathrm{~dB}$ (main beam) \\
\hline Antenna size & $111.5 \mathrm{~mm} \times 96.06 \mathrm{~mm}$ \\
\hline Beamwidth (max) & $120^{\circ}$ (azimuth) $\times 120^{\circ}$ (elevation) \\
\hline
\end{tabular}

Table II. Dimensions (in millimeter) of the proposed array antenna. Parameters: $\mathrm{L}_{\mathrm{A}}, \mathrm{W}_{\mathrm{A}}, \mathrm{L}_{\mathrm{T}}, \mathrm{W}_{\mathrm{T}}, \mathrm{L}_{\mathrm{UC}}, \mathrm{W}_{\mathrm{UC}}, \mathrm{Sv}, \mathrm{Sh}, \mathrm{Sg}$, and UC represent the antenna's length, antenna's width, size of three unit-cell inter-spaced length, size of three unit-cell inter-spaced width, unit-cell length, unit cell width, inter-element spacing between slot spirals in the elevation plane (ISep), inter-element spacing between slot spirals in the azimuth plane (ISap), spiral width ( $\mathrm{Sw})$, spiral gap $(\mathrm{Sg})$, and unit-cell, respectively.

\begin{tabular}{|c|c|c|c|c|c|c|c|c|c|}
\hline $\mathrm{L}_{\mathrm{A}}$ & $\mathrm{W}_{\mathrm{A}}$ & $\mathrm{L}_{\mathrm{T}}$ & $\mathrm{W}_{\mathrm{T}}$ & $\mathrm{L}_{\mathrm{UC}}$ & $\mathrm{W}_{\mathrm{UC}}$ & ISep & ISap & $\mathrm{Sw}$ & $\mathrm{Sg}$ \\
\hline 111.5 & 96.06 & 55.75 & 32.02 & 18.58 & 16.01 & 2.07 & 4.15 & 1.0 & 1.0 \\
\hline
\end{tabular}

The proposed CP-SAR antenna is constituted from an array of antenna unit-cells, as shown in Fig. 1, that comprise slot spiral structures that act as a series lefthanded (LH) capacitances [20][21]. By arranging the unit-cells in a rectangular array the antenna's beam shape and direction can be precisely controlled. The surface area of the antenna and inter-unit cell separation determine the antenna gain. It is also shown here that the array extends the spiral antenna bandwidth from $25 \%$ to $173 \%$. Dimensions of the radiating unit elements and inter-element spacing specified in Table II were determined from simulation analysis.

The design and optimization process was carried out using a method-of-moment (MoM) analysis using High Frequency Structure Simulator (HFSS ${ }^{\mathrm{TM}}$ ). The antenna consisting of $6 \times 6$ arrangement of slot spiral elements, depicted in Fig. 1, was fabricated and its performance measured. The simulated and measured results presented in Section III confirm the antenna satisfied the target specification for the proposed CP-SAR antenna. The discrepancy between the simulated and measured results is attributed to fabricated tolerance and imperfect solder connection to the feed-line.

\section{A) Analysis of the Radiating Elements}

Creation of $\mathrm{CP}$ radiation requires the unit-cell to be excited with orthogonal (in-phase and quadrature) fields of equal amplitude. In [22] it has been shown that a single feed-line can be used to excite CP radiation in a circular patch. In fact, the radiation can be made to be either lefthanded or right-handed circularly polarized
(LHCP/RHCP) depending on the feed point to the antenna element [23]. Also the best $\mathrm{CP}$ radiation is achieved when the eccentricity is in the range 0.8-0.9.

Fig. 2 shows the layout of the proposed radiating element used in array antenna shown in Fig. 1. The Archimedean microstrip spiral length is chosen to be a wavelength long. The size of the spiral is calculated from the lowest and the highest frequency of the operating frequency range:

$$
\begin{aligned}
& f_{\text {low }}=\frac{c}{2 \pi a \sqrt{\varepsilon_{\text {eff }}}} \\
& f_{\text {high }}=\frac{c}{2 \pi x \sqrt{\varepsilon_{\text {eff }}}}
\end{aligned}
$$

Where " $a$ " and " $x$ " are defined in Fig. 2. An array of spirals can be designed to operate over a certain predefined frequency range. The single element is constructed by printing an optimized slot spiral on the radiating patch to realize the series $\mathrm{LH}$ capacitance, $C_{L}$. With the omission of shunt LH inductance, $L_{L}$, the single radiating element based on SCRLH-TL has been reported in [20][21]. Unlike CRLH-TL, the SCRLH-TL resonates at zeroth and positive modes rather than negative order modes due to the absence of $C_{L}$ or $L_{L}$. Therefore, the electrical size of the SCRLH-TL structure can be reduced. When SCRLH-TL structure radiating at positive modes, the antenna obtains a higher efficiency compared with radiating at the zeroth and negative modes. This property makes SCRLH-TL suitable for designing UWB antennas that have a small physical footprint [20][21].

The antenna was fabricated on Rogers RT5880 (lossy) substrate of thickness of $5 \mathrm{~mm}$ and dielectric 
constant of 2.2. This substrate was chosen in order to enhance its bandwidth and radiation characteristics, and also to avoid high power dielectric breakdown of the antenna. The antenna is terminated with a $50 \mathrm{Ohm}$ load to prevent standing waves being established in the antenna structure, which would otherwise compromise the efficiency of the Archimedean spiral antenna elements.

Proximity-coupled feed method [24] is adopted in the antenna design presented here, which allows easy adjustment of the impedance matching. This technique can also improve the bandwidth and reduce parasitic radiation from the feeding network. Dimensions of the circular patch radiator and the ground-plane are: $a=6.4$ $\mathrm{mm}, b=6.8 \mathrm{~mm}$ and $L_{g} \times W_{g}=111.5 \times 96.06 \mathrm{~mm}^{2}$. Interelement spacing in the array antenna is $4.15 \mathrm{~mm}$ $\left(0.004 \lambda_{0}\right)$ and $2.07 \mathrm{~mm}\left(0.002 \lambda_{0}\right)$ in the azimuth (ISap) and elevation (ISep) planes, respectively, and where $\lambda_{0}$ is free-space wavelength at $300 \mathrm{MHz}$. The feeder network performance was optimized using HFSS ${ }^{\mathbf{T M}}$. Microstrip feeding mechanism was located in the elevation plane to realize the desired amplitude and phase [25]. It was observed that series feed-line resulted in as much as $40^{\circ}$ phase variation at the band edge, and more than $1 \mathrm{~dB}$ ripple in the elevation plane pattern. Patches in the azimuth plane were fed out of phase to achieve better cross polarization in the azimuth plane. The top layer of the microstrip array radiator in Fig. 1 has a size of $105.5 \times 93 \mathrm{~mm}^{2}$. The ground-plane is used to provide a protective electromagnetically shield to electronic components in the wireless system.

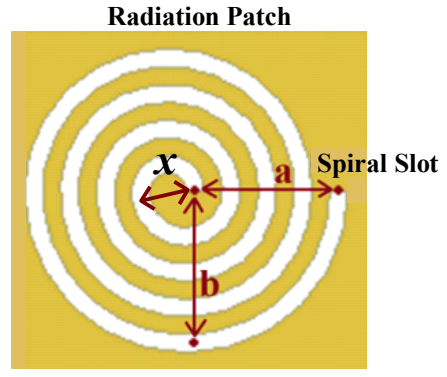

Fig. 2. Layout of radiating unit-cell element, where " $a$ " is dimension of semi-minor axis, and " $b "$ is dimension of semi-major axis.

The single CP radiator, shown in Fig. 2, can generate LHCP by rotating the patch by $-45^{\circ}$ around the center of the circle. HFSS ${ }^{\mathrm{TM}}$ was used to optimize the size parameters of the radiator. Measured results in Fig. 3 reveal how the dimensions of the semi-minor $(a)$ and semi-major $(b)$ axis influence the unit-cells CP frequency and the axial-ratio (AR) of the antenna while the other parameters were kept constant. Optimum values determined over the frequency range $850 \mathrm{MHz}-4.15$ GHz are: $a=6.4 \mathrm{~mm}$ and $b=6.8 \mathrm{~mm}$. Best CP radiation is achieved for the eccentricity ranging from $12 \%-22 \%$.

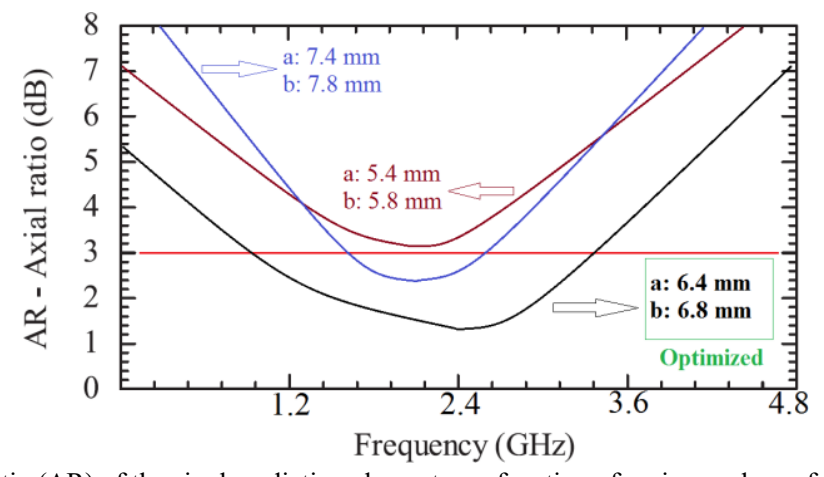

Fig. 3. Measured axial-ratio (AR) of the single radiating element as a function of various values of the semi-minor axis and semi-major axis.

\section{RESUltS AND DiSCUSSION ON THE ANTENNA PERFORMANCE}

The desired goals of the planar array antenna were to achieve beam scanning of $120^{\circ}, 3-\mathrm{dB}$ main beamwidth of $120^{\circ} \pm 2.5^{\circ}$ in the elevation and azimuth planes, crosspolarization radiation suppression better than $-40 \mathrm{~dB}$, and a peak gain of $5 \mathrm{dBi}$. The first step carried out was to determine the number of elements, and the amplitude and phase distribution of the individual elements. The number of elements required in the elevation and azimuth plane was six. Pattern synthesis based on Woodward techniques [26] was used to determine the complex excitation coefficients for the individual array elements to achieve the required pattern shape. The illumination pattern was achieved by applying a specific amplitude and phase to the patches in the array according to the excitation coefficient outlined in Table III.

Array analysis was carried out to determine the optimum inter-element spacing to achieve the required scanning angles from the proposed antenna, i.e. approximately $120^{\circ}$ in the elevation and azimuth planes, to avoid grating lobe and scan blindness. To realize this, the six radiating elements in the elevation and azimuth planes had to have inter-element spacing of $0.002 \lambda_{0}$ (which $\lambda_{0}$ is free space wavelength at $300 \mathrm{MHz}$ ) or 2.07 
$\mathrm{mm}$ in the elevation plane and $0.004 \lambda_{0}$ or $4.15 \mathrm{~mm}$ in the azimuth plane.

The feed network consisting of a strip-line configuration was locating on the bottom side of the radiating elements to prevent any spurious radiation from it degrading the radiation pattern of the array antenna. The feed network was optimized for optimum bandwidth, gain and radiation efficiency.

Tables III. Excitation coefficients applied to the radiation elements in the azimuth and elevation planes.

Azimuth plane (xy-plane)
\begin{tabular}{|c|c|c|c|c|c|c|}
\hline Element number & 1 & 2 & 3 & 4 & 5 & 6 \\
\hline Relative amplitude & 3.45 & 6.12 & 10 & 10 & 7.50 & 4.65 \\
\hline Relative phase & $-180^{0}$ & $-90^{0}$ & $0^{0}$ & $0^{0}$ & $90^{0}$ & $180^{0}$ \\
\hline
\end{tabular}
\begin{tabular}{|c|c|c|c|c|c|c|}
\hline Element number & 1 & 2 & 3 & 4 & 5 & 6 \\
\hline Relative amplitude & 11.15 & 14.25 & 20 & 20 & 16.50 & 12.62 \\
\hline Relative phase & $-180^{0}$ & $-90^{\circ}$ & $0^{0}$ & $0^{0}$ & $90^{0}$ & $180^{\circ}$ \\
\hline
\end{tabular}

Polarization purity of an antenna system is an important characteristic, particularly in dual polarized wireless systems, where depolarization can prevent the system's quality objectives from being achieved. Hence, one of the objectives of the antenna design was to achieve cross-polarization level of better than $-40 \mathrm{~dB}$. Cross-polarization suppression technique was applied to achieve low cross-polarization level [27]. This was achieved using a number of techniques. Firstly, the antenna was fed from opposite directions with a phase difference of $180^{\circ}$ in order to cancel out the current components induced in orthogonal port. Fig. 4 shows the amplitude and phase in orthogonal planes at each radiating element. Further suppression in crosspolarization was achieved by mirroring the groups of radiating spirals about the vertical $y$-direction. The same scheme was applied to the groups of radiating spirals in $x$-direction.

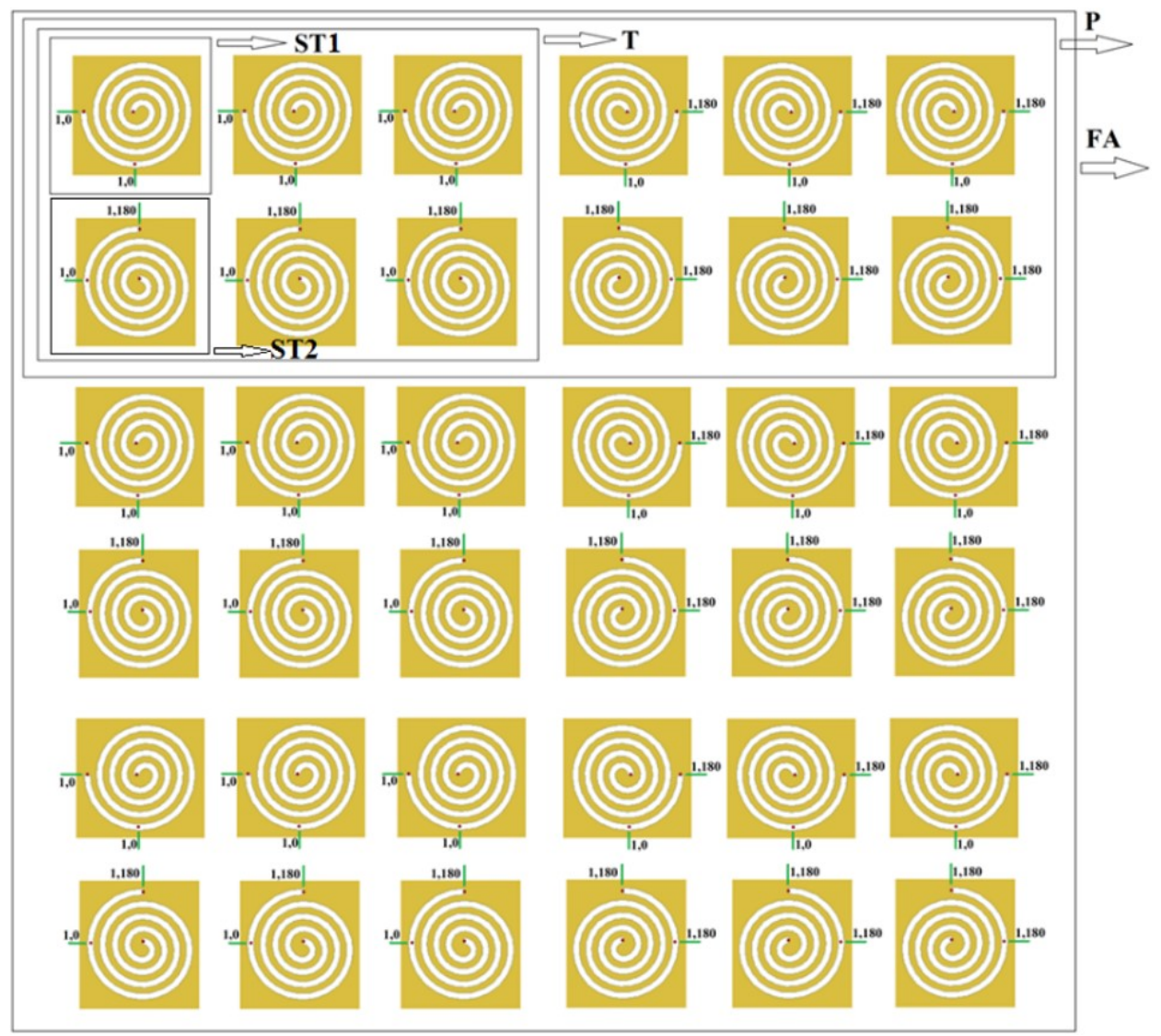


Fig. 4. Cross-polarization suppression techniques applied to the proposed array antenna. Size of sub-tile 1 (ST1) is: $18.58 \times 16.01 \mathrm{~mm}^{2}$; size of subtile 2 (ST2) is: $16.01 \times 18.58 \mathrm{~mm}^{2}$; tile (T) size is: $55.75 \times 32.02 \mathrm{~mm}^{2}$; panel (P) size is: $105.5 \times 32.02 \mathrm{~mm}^{2}$; full antenna (FA) size is: $105.5 \times 93 \mathrm{~mm}$; and size of ground-plane is $111.5 \times 96.06 \mathrm{~mm}^{2}$. Azimuth is in the $x y$-plane, and the elevation is in the $z y$-plane.

The proposed planar array antenna shown in Fig. 4 was

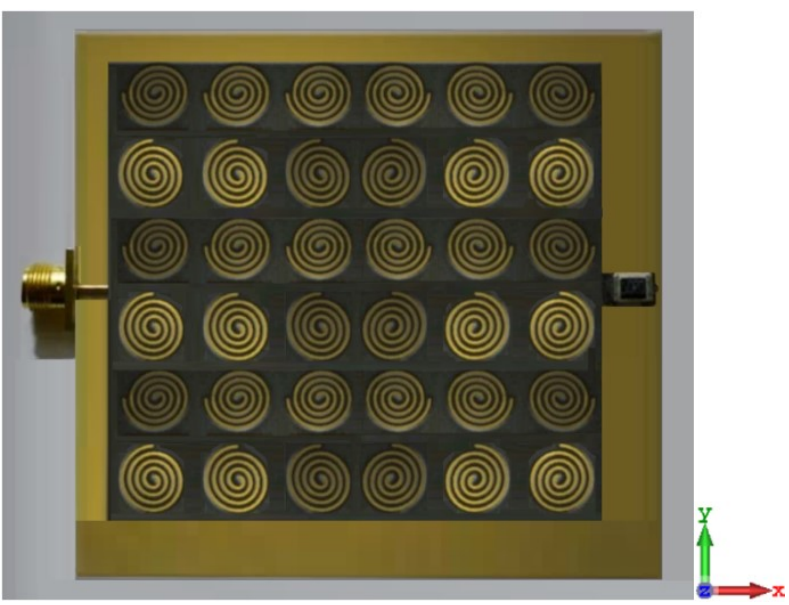

Fig. 5. Photograph of the proposed microstrip SAR array antenna. fabricated and its characteristics measured. Photograph of the antenna is shown in Fig. 5. The antenna's reflection coefficient and input impedance were measured with a RF Vector Network Analyzer (Agilent E5062A). The antenna gain, axial-ratio, and radiation patterns were measured inside the anechoic chamber of dimensions $5 \times 9 \times 3 \mathrm{~m}^{3}$ using a standard reference conical log spiral antenna.

The experimental and simulation results are shown in Figs. 6-11. Fig. 6 shows the frequency dependence of reflection coefficient. The measured impedance bandwidth for $\mathrm{S}_{11}<-10 \mathrm{~dB}$ is $3.85 \mathrm{GHz}$ extending from $300 \mathrm{MHz}$ to $4.15 \mathrm{GHz}$, which is equivalent to a fractional bandwidth of $173 \%$. The operational bandwidth of the antenna includes UHF, L-band, S-band, and partially Cband. Compared to conventional half-wavelength antennas the proposed antenna with a significantly smaller form factor covers a large bandwidth. This is the advantage of the proposed metamaterial composite right/left-handed transmission-line antenna.

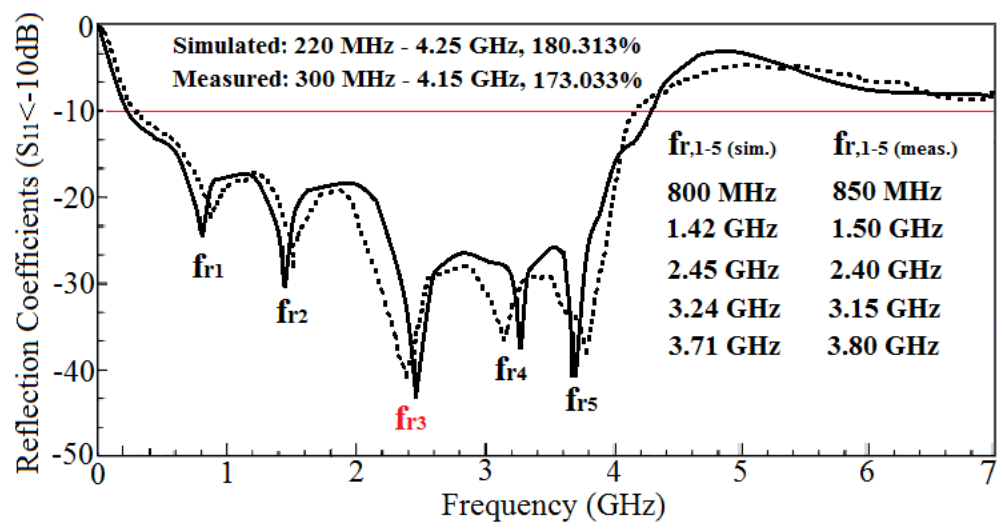

Fig. 6. Simulated and measured reflection coefficient response.

Input impedance of the antenna is shown in Fig. 7, and the corresponding resistance and reactance values at various frequencies are listed in the Table IV. The average impedance is $49.6+\mathrm{j} 5.4 \mathrm{ohms}$ across $220 \mathrm{MHz}$ to $4.15 \mathrm{GHz}$. There is good agreement between the measured and simulated results, and the small discrepancy is attributed to resistivity of the SMA connector and solder. 




Fig. 7. Simulated and measured input impedances $\left(Z_{\text {in }}\right)$ vs. frequency.

Table IV. Simulated and measured input impedances at various frequencies.

\begin{tabular}{|c|c|c|c|c|c|c|c|}
\hline \multirow{2}{*}{ Simulated } & $220 \mathrm{MHz}$ & $800 \mathrm{MHz}$ & $1.42 \mathrm{GHz}$ & $2.45 \mathrm{GHz}$ & $3.24 \mathrm{GHz}$ & $3.71 \mathrm{GHz}$ & $4.25 \mathrm{GHz}$ \\
\cline { 2 - 8 } & $58+\mathrm{j} 2$ & $50+\mathrm{j} 3$ & $46+\mathrm{j} 9.5$ & $50+\mathrm{j} 7.5$ & $48+\mathrm{j} 5.5$ & $51+\mathrm{j} 6$ & $52+\mathrm{j} 5.5$ \\
\hline \hline \multirow{2}{*}{ Measured } & $300 \mathrm{MHz}$ & $850 \mathrm{MHz}$ & $1.50 \mathrm{GHz}$ & $2.40 \mathrm{GHz}$ & $3.15 \mathrm{GHz}$ & $3.80 \mathrm{GHz}$ & $4.15 \mathrm{GHz}$ \\
\cline { 2 - 8 } & $55+\mathrm{j} 2.5$ & $46.5+\mathrm{j} 3.1$ & $44+\mathrm{j} 8$ & $48+\mathrm{j} 8$ & $49+\mathrm{j} 8$ & $48+\mathrm{j} 7.8$ & $49+\mathrm{j} 7$ \\
\hline
\end{tabular}

The simulated and measured antenna gain, radiation efficiency, and axial-ratio of the proposed antenna are shown in Fig. 8 and tabulated in Table V. The simulated and measured results start from $220 \mathrm{MHz}$ and $300 \mathrm{MHz}$, respectively. Maximum gain and radiation efficiency measured are $4.8 \mathrm{dBi}$ and $79.5 \%$, respectively, at 2.40 $\mathrm{GHz}$, which are lower than the simulated values by about $0.5 \mathrm{dBi}$ and $6 \%$, respectively. AR is a crucial parameter for defining circularly polarization. Fig. 8(b) shows the measured 3-dB AR bandwidth is $3.97 \mathrm{GHz}$ from $250 \mathrm{MHz}$ to $4.22 \mathrm{GHz}$. The optimized value of $\mathrm{AR}$ is $0.47 \mathrm{~dB}$ at 2.4 $\mathrm{GHz}$. As mentioned earlier the discrepancy between the simulated and measured results is attributed to fabrication tolerance and imperfect soldering connection to the feedline.

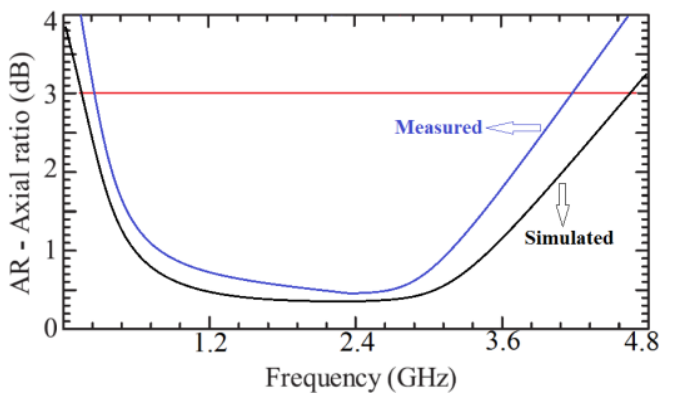

(b) Axial-ratio (a) Gain and radiation efficiency as a function of frequency.



Fig. 8. Characteristics of the proposed antenna: (a) Gain and radiation efficiency as a function of frequency, and (b) AR vs. frequency at $\theta=0^{\circ}$.

Table V. Bandwidth, radiation characteristics and axial-ratio (AR) of the proposed antenna.

Antenna Characteristics

\begin{tabular}{|c|c|c|c|c|c|c|c|c|}
\hline \multirow{6}{*}{ Simulated } & $\begin{array}{c}\text { Bandwidth }(\mathrm{GHz}) / \\
\text { Fractional bandwidth (\%) }\end{array}$ & \multicolumn{3}{|c|}{$0.22-4.25 \mathrm{GHz}$} & \multicolumn{4}{|c|}{$180.3 \%$} \\
\hline & \multirow{2}{*}{ Gain (dBi) } & $0.22 \mathrm{GHz}$ & $0.8 \mathrm{GHz}$ & $1.42 \mathrm{GHz}$ & $2.45 \mathrm{GHz}$ & $3.24 \mathrm{GHz}$ & $3.71 \mathrm{GHz}$ & $4.25 \mathrm{GHz}$ \\
\hline & & 0.71 & 1.23 & 2.55 & 5.5 & 3.95 & 2.88 & 1.97 \\
\hline & \multirow{2}{*}{ Radiation efficiency (\%) } & $0.22 \mathrm{GHz}$ & $0.8 \mathrm{GHz}$ & $1.42 \mathrm{GHz}$ & $2.45 \mathrm{GHz}$ & $3.24 \mathrm{GHz}$ & $3.71 \mathrm{GHz}$ & $4.25 \mathrm{GHz}$ \\
\hline & & 24.8 & 47.6 & 63.7 & 86.2 & 74.1 & 63.9 & 54.8 \\
\hline & Axial-ratio $(\mathrm{dB})$ & $0.22 \mathrm{GHz}$ & $0.8 \mathrm{GHz}$ & $1.42 \mathrm{GHz}$ & $2.45 \mathrm{GHz}$ & $3.24 \mathrm{GHz}$ & $3.71 \mathrm{GHz}$ & $4.25 \mathrm{GHz}$ \\
\hline
\end{tabular}




\begin{tabular}{|c|c|c|c|c|c|c|c|c|}
\hline & & 2.7 & 0.7 & 0.43 & 0.36 & 0.65 & 1.32 & 2.30 \\
\hline \multirow{7}{*}{ Measured } & $\begin{array}{c}\text { Bandwidth (GHz) / } \\
\text { Fractional bandwidth (\%) }\end{array}$ & & $0.30-4.15$ & & & & $3 \%$ & \\
\hline & \multirow{2}{*}{ Gain (dBi) } & $0.3 \mathrm{GHz}$ & $0.85 \mathrm{GHz}$ & $1.5 \mathrm{GHz}$ & $2.4 \mathrm{GHz}$ & $3.15 \mathrm{GHz}$ & $3.8 \mathrm{GHz}$ & $4.15 \mathrm{GHz}$ \\
\hline & & 0.5 & 0.96 & 2.26 & 4.8 & 3.51 & 2.43 & 1.84 \\
\hline & \multirow{2}{*}{ Radiation efficiency (\%) } & $0.3 \mathrm{GHz}$ & $0.85 \mathrm{GHz}$ & $1.5 \mathrm{GHz}$ & $2.4 \mathrm{GHz}$ & $3.15 \mathrm{GHz}$ & $3.8 \mathrm{GHz}$ & $4.15 \mathrm{GHz}$ \\
\hline & & 20 & 43.8 & 58.6 & 79.5 & 66.4 & 57.1 & 50.5 \\
\hline & \multirow{2}{*}{ Axial-ratio $(\mathrm{dB})$} & $0.3 \mathrm{GHz}$ & $0.85 \mathrm{GHz}$ & $1.5 \mathrm{GHz}$ & $2.4 \mathrm{GHz}$ & $3.15 \mathrm{GHz}$ & $3.8 \mathrm{GHz}$ & $4.15 \mathrm{GHz}$ \\
\hline & & 2.7 & 0.95 & 0.65 & 0.47 & 0.90 & 2.28 & 2.95 \\
\hline
\end{tabular}

The measured gain, radiation efficiency, and AR at various azimuth angles between $A z=0^{\circ}$ and $180^{\circ}(x-z$ plane), and between $A z=90^{\circ}$ and $270^{\circ}(y-z$ plane) and at various operating frequencies from $0.3 \mathrm{GHz}$ to $4.15 \mathrm{GHz}$ are shown in Figs. 9 and 10, and tabulated in Tables VI and VII.

Table VI. Measured maximum gain beamwidth (MG-B), maximum radiation efficiency beamwidths (MRE-B), and the 3-dB axial-ratio beamwidth (AR-B) in the $\theta$ plane $x-z$ plane at spot frequencies in the operating range.

\begin{tabular}{|c|c|c|c|c|c|c|c|}
\hline Frequency $(\mathrm{GHz})$ & $f_{\text {start }}=0.30$ & $f_{r_{1}}=0.85$ & $f_{r_{2}}=1.50$ & $f_{r_{3}}=2.40$ & $f_{r_{4}}=3.15$ & $f_{r_{5}}=3.80$ & $f_{\text {end }}=4.15$ \\
\hline MG-B & $20^{\circ}$ & $36^{\circ}$ & $10^{\circ}$ & $0^{\circ}$ & $60^{\circ}$ & $120^{\circ}$ & $150^{\circ}$ \\
\hline MRE-B & $24^{\circ}$ & $40^{\circ}$ & $12^{\circ}$ & $0^{\circ}$ & $64^{\circ}$ & $125^{\circ}$ & $162^{\circ}$ \\
\hline 3-dB AR-B & $16^{\circ}$ & $30^{\circ}$ & $8^{\circ}$ & $0^{\circ}$ & $55^{\circ}$ & $130^{\circ}$ & $158^{\circ}$ \\
\hline
\end{tabular}

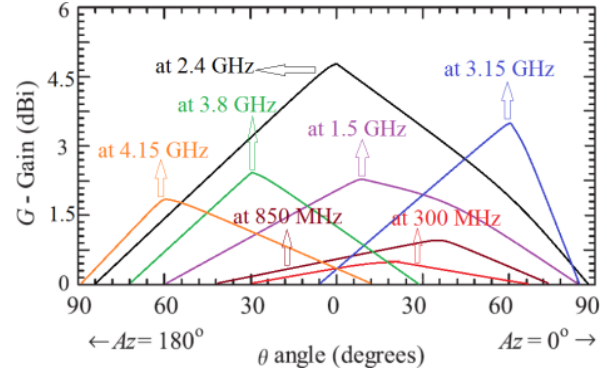

(a)

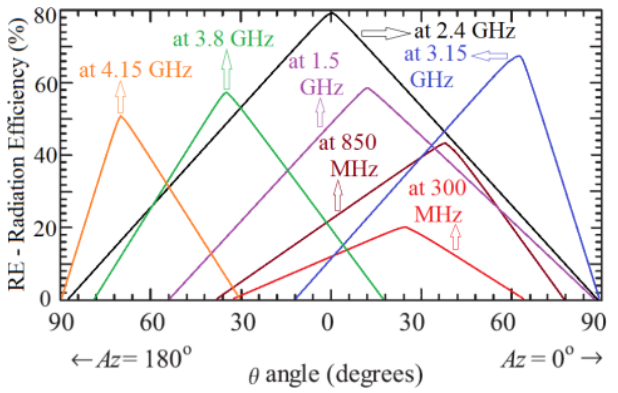

(b)



(c)

Fig. 9. (a) Gain, (b) Radiation efficiency, and (c) AR versus angle $\theta$ in the $x-z$ plane at spot frequencies in the operating range. 




(a)

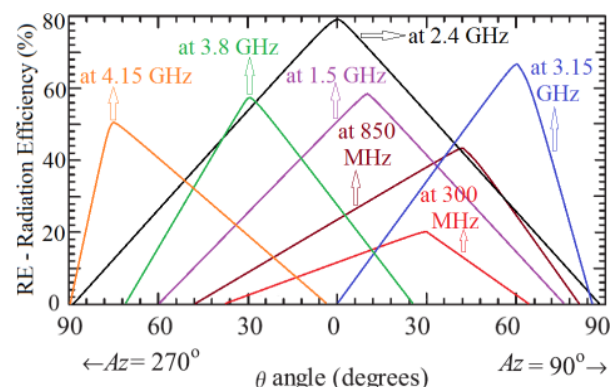

(b)

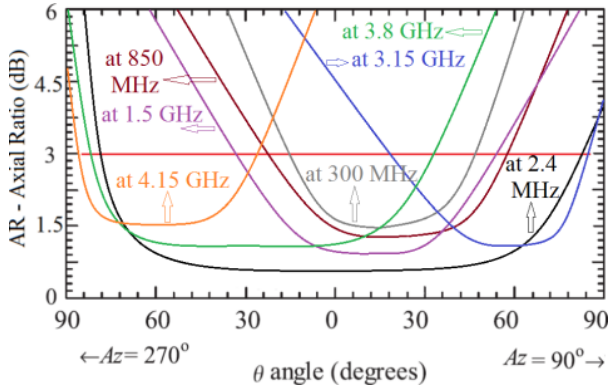

(c)

Fig. 10. (a) Gain, (b) radiation efficiency, and (c) AR versus angle $\theta$ in the $y$ - $z$ plane at spot frequencies in the operating range.

Table VII. Measured maximum gain beamwidth (MG-B), maximum radiation efficiency beamwidths (MRE-B), and the 3-dB axial-ratio beamwidth (AR-B) in the $\theta$ plane $y-z$ plane at spot frequencies in the operating range.

\begin{tabular}{|c|c|c|c|c|c|c|c|}
\hline Frequency $(\mathrm{GHz})$ & $f_{\text {start }}=0.30$ & $f_{r_{1}}=0.85$ & $f_{r_{2}}=1.50$ & $f_{r_{3}}=2.40$ & $f_{r_{4}}=3.15$ & $f_{r_{5}}=3.80$ & $f_{\text {end }}=4.15$ \\
\hline MG-B & $18^{\circ}$ & $33^{\circ}$ & $15^{\circ}$ & $0^{\circ}$ & $55^{\circ}$ & $117^{\circ}$ & $156^{\circ}$ \\
\hline MRE-B & $30^{\circ}$ & $42^{\circ}$ & $10^{\circ}$ & $0^{\circ}$ & $60^{\circ}$ & $120^{\circ}$ & $165^{\circ}$ \\
\hline 3-dB AR-B & $17^{\circ}$ & $24^{\circ}$ & $12^{\circ}$ & $0^{\circ}$ & $60^{\circ}$ & $118^{\circ}$ & $150^{\circ}$ \\
\hline
\end{tabular}

Fig. 11 shows the measured gain patterns between $A z$ $=0^{\circ}$ and $90^{\circ}$ of the proposed $6 \times 6$ circular microstrip element array. The plots show the co- and crosspolarizations radiation patterns for RHCP and LHCP elements. The beam patterns are applicable for CP-SAR operation in both the azimuth and elevation planes. The nearest side lobe is suppressed by about $-15 \mathrm{~dB}$. From the measurement, it has also turned out that the array achieves a 3-dB AR bandwidth of $3.94 \mathrm{GHz}$ centered at $\sim 2.4 \mathrm{GHz}$. The results show no scan blindness occurs in the main beam over $120^{\circ}$ and the mutual coupling between elements is less than $-15 \mathrm{~dB}$. The maximum gain and radiation efficiency measured at $2.40 \mathrm{GHz}$ are $\sim 5$ $\mathrm{dBi}$ and $\sim 80 \%$, and the cross-polarization level is $-45 \mathrm{~dB}$. The beamwidths at both azimuth and elevation planes are between $60^{\circ}$ and $120^{\circ}$ over the operational frequencies. Compared to the single radiating element, which exhibits a fractional bandwidth of $25 \%$, the proposed array has a fractional bandwidth of $173 \%$. 

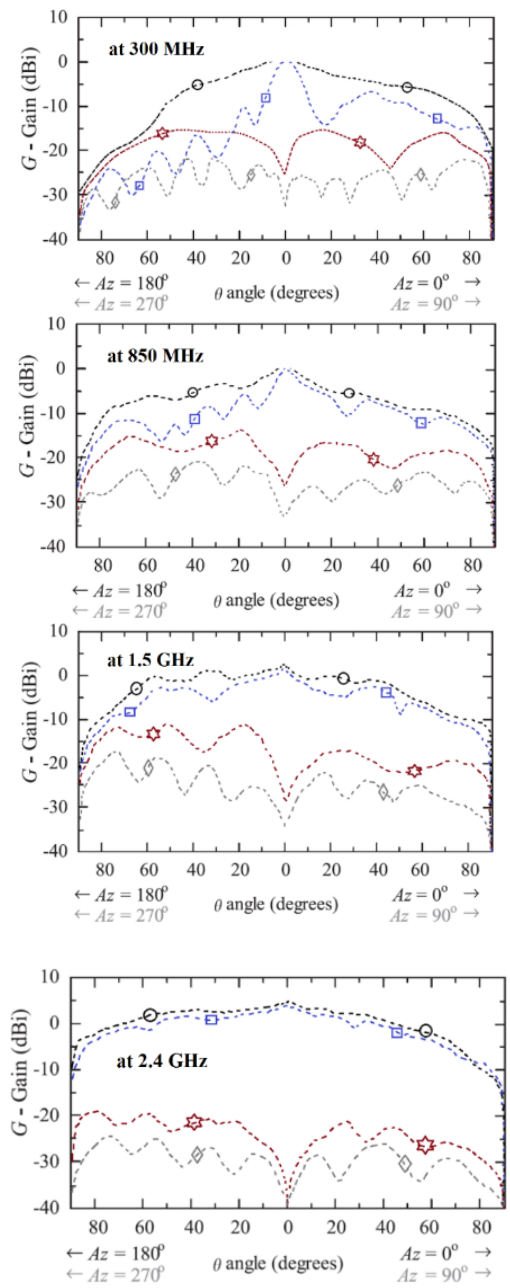
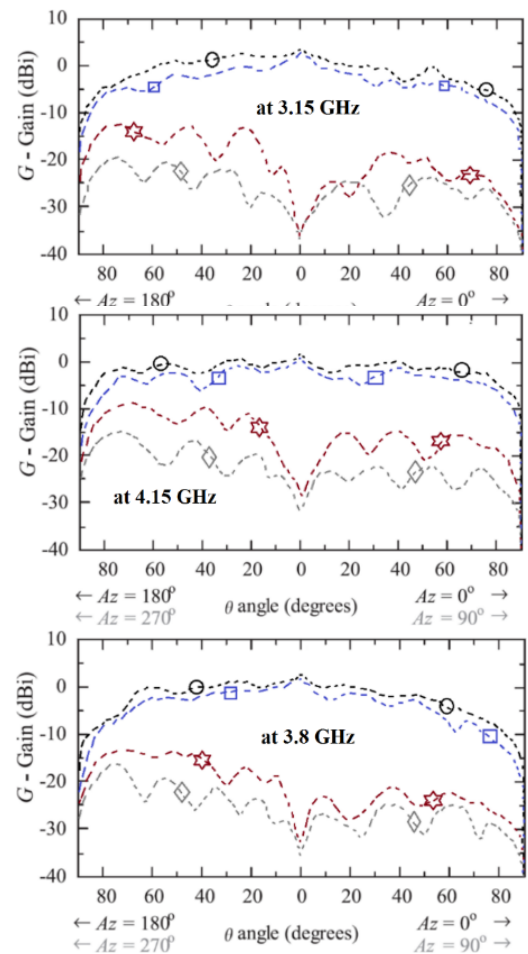

Fig. 11. Measured radiation gain of the $6 \times 6$ circular microstrip SAR array antenna at various spot frequencies in the operating range. (CoPol. elevation pattern at E-plane, Co-Pol. azimuth pattern at H-plane, Cross-Pol. elevation pattern at E-plane, and Cross-Pol. azimuth pattern at H-plane are represented by black dotted line with circle, blue dotted line with square, red dotted line with pentagon, and grey dotted line with lozenge, respectively.

\section{CONCLUSIONS}

Planar array antenna is shown to meet the stringent requirements for circularly polarized synthetic aperture radar (CP-SAR) systems operated in UHF, L, S and CBands in L-Band. The antenna consists of $6 \times 6$ matrix slot spiral that effectively act as simplified composite right/left-handed transmission-line elements. The design and optimization process was carried out using methodof-moment analysis software. To achieve the required radiation pattern shape the magnitude of the amplitude and phase applied to the individual array elements was determined using a pattern synthesis technique. The measured performance of the antenna satisfies the specifications for CP-SAR onboard UAV.

\section{DisClOSURE STATEMENT}

No potential conflict of interest was reported by the authors. 


\section{REFERENCES}

[1] Y. K. Chan, V. C. Koo, "An introduction to synthetic aperture radar (SAR)” Prog. Electromag. Res. B, vol. 2, 2008, pp. 27-60.

[2] Skolnik, M. I., Radar Handbook, McGraw-Hill, 1970.

[3] R. Birk, W. Camus, E. Valenti, W. J. McCandless, "Synthetic aperture radar imaging systems," IEEE Aerosp. Electronic Syst. Mag. vol. 10, 1995, pp. 15-23.

[4] M. Baharuddin, V. Wissan, J. T. S. Sumantyo, H. Kuze, "Elliptical microstrip antenna for circularly polarized synthetic aperture radar," J. Electron. Comm., vol. 65, 2011, pp. 62-67.

[5] P. R. Akbar, H. Saito, M. Zhang, J. Hirokawa, M. Ando, "Parallel-plate slot array antenna for deployable SAR antenna onboard small satellite," IEEE Transactions on Antennas and Propagation, Vol. 64, Issue 5, 2016, pp. 1661 - 1671.

[6] Y. Asrizal, J. T. S. Sumantyo, "Design of tilted beam circularly polarized antenna for CP-SAR sensor onboard UAV," 2016 Int. Symp. on Ant. and Propagation (ISAP), 2016, pp. 658 - 659

[7] B. Pyne, P. Akbar, H. Saito, M. Zhang, J. Hirokawa, M. Ando, "Design of a center-feed waveguide feeder for wideband rectangular parallel-plate slot-array antenna-board space-borne X-band SAR system," 2016 European Radar Conference (EuRAD), 2016, pp. $386-389$.

[8] J.-D. Zhang, L. Zhu, Q.-S. Wu, N.-W. Liu, W. Wu, “A compact microstrip-fed patch antenna with

enhanced bandwidth and harmonic suppression," IEEE Transactions on Antennas and Propagation, vol. 64, issue 12, 2016, pp. $5030-5037$.

[9] S. D. Targonski, D.M. Pozar, "Design of wide band circularly polarised aperture coupled microstrip antennas," IEEE Trans. Antennas, vol. 41, 1993, pp. 214-220.

[10] C. H. Taso, Y. M. Hwang, F. Killburg, F. Dietrich, "Aperture coupled patch antenna with wide bandwidth and dual polarization capabilities," IEEE Antenna Propag. Soc. Symp. Dig., New York, June 1988, pp. 936-939.

[11] M. Alibakhshikenari, M. Naser-Moghadasi, R. A. Sadeghzadeh, B. S. Virdee, E. Limiti (April 26, 2017). Chapter on "Planar antennas for reliable multiband RF communications," Metamaterials - Devices and Advanced Applications, Dr. Alejandro Lucas Borja (Ed.), ISBN 978-953-51-4926-2.

[12] M. Alibakhshi-Kenari, M. Naser-Moghadasi, R. A. Sadeghzadeh, "Composite right-left-handed-based antenna with wide applications in very-high frequency-ultra-high frequency bands for radio transceivers," IET Microwaves, Antennas \& Propagation, vol.9, Dec., 2015, pp. 1713 - 1726.

[13] M. Alibakhshi-Kenari, M. Naser-Moghadasi, R. A. Sadeghzadeh, B. S. Virdee and E. Limiti, "New CRLH-Based Planar Slotted Antennas with Helical Inductors for Wireless Communication Systems, RF-Circuits and Microwave Devices at UHF-SHF Bands", Wireless Personal CommunicationsSpringer Journal, Wireless Personal Communications, Feb. 2017, vol. 92, issue 3, pp 1029-1038.

[14] M. Alibakhshi-Kenari, M. Naser-Moghadasi, R. A. Sadeghzadeh, B. S. Virdee and E. Limiti, "A New Planar Broadband Antenna Based on Meandered Line Loops for Portable Wireless Communication Devices" Radio Science, vol. 51, issue 7, July 2016, pp. 1109-1117.

[15] M. Alibakhshi-Kenari, M. Naser-Moghadasi, R. A. Sadeghzadeh, B. S. Virdee and E. Limiti, "Periodic Array of Complementary Artificial Magnetic Conductor MetamaterialsBased Multiband Antennas for Broadband Wireless Transceivers" IET Microw. Ant. \& Propag. vol. 10, issue 15, 2016, pp. $1682-1691$.

[16] C. L. Mak, K. M. Luk, Y. L. Chow, "Experimental study of a microstrip patch antenna with an L-shaped probe," IEEE Trans. Antennas Propag., vol. 48, 2000, pp. 777-783.

[17] K. Yu, Y. Li, Y. Wang, "Multi-band metamaterial-based microstrip antenna for WLAN and WiMAX applications," IEEE Int. Applied Computational Electromag. Society Symp., 2017, pp. 1-2.
[18] H. N. Quang, H. Shirai, "A compact D-CRLH metamaterial antenna for WLAN and WiMAX Multiband," IEEE Int. Symp. on Antennas and Propagation (ISAP), 2016, pp. $32-33$

[19] G. S. Rajesh, K. V. Kishore, V. Kumar, "Multiband microstrip patch antenna design using metamaterial for airborne SAR system," IEEE Int. Conf. on Signal Processing, Informatics, Communication and Energy Systems (SPICES), 2015, pp. 1-3.

[20] M. Alibakhshi-Kenari, M. Naser-Moghadasi, R. A. Sadeghzadeh, B. S. Virdee, E. Limiti, "New compact antenna based on simplified CRLH-TL for UWB wireless communication systems", Int. Journ. of RF \& Microwave Computer-Aided Eng., vol. 26, issue 6, 2016, pp. 217-225.

[21] C. Zhou, G. Wang, J. Liang, Y. Wang, B. Zong, "Broadband Antenna Employing Simplified MTLs for WLAN/WiMAX Applications," IEEE Antennas and Wireless Propagation Letters, vol. 13, 2014, pp.595-598.

[22] M. C. Bailey, M. D. Deshpande, "Analysis of elliptical and circular microstrip antennas using moment method," IEEE Trans. Antennas Propagation, vol. 33, 1985, pp. 954-959.

[23] C. S. Shen, "The elliptical microstrip antenna with circular polarization," IEEE Trans. Ant. Propag., vo. 29, 1981, pp. 9094.

[24] D. M. Pozar and D. H. Schaubert, Microstrip antenna, IEEE Press, New York, 1995.

[25] S. B. Sharma, S. Kulshrestha, B. K. Pandey, D. K. Sharma, R. Jyoti, S. B. Chakrabarty, "Shaped beam printed antenna with waveguide power divider for synthetic aperture radar applications," Microwave Opt. Technol Lett., vol. 49, No. 4, 2007 , pp. $832-835$.

[26] S. B. Chakrabarty, M. Khanna, S. B. Sharma, "Wideband planar array antenna in C-band for synthetic aperture radar applications," Microw. Opt. Tech. Lett., vol. 33, 2002, pp. 52 54.

[27] D. K. Sharma, B. K. Pandey, S. Kulshrestha, S. B. Chakrabarty, R. Jyoti, "Design of wideband microstrip antenna array at Lband for synthetic aperture radar applications," Microwave Opt. Technol. Lett., vol. 55, 2013, pp. 903 - 908. 